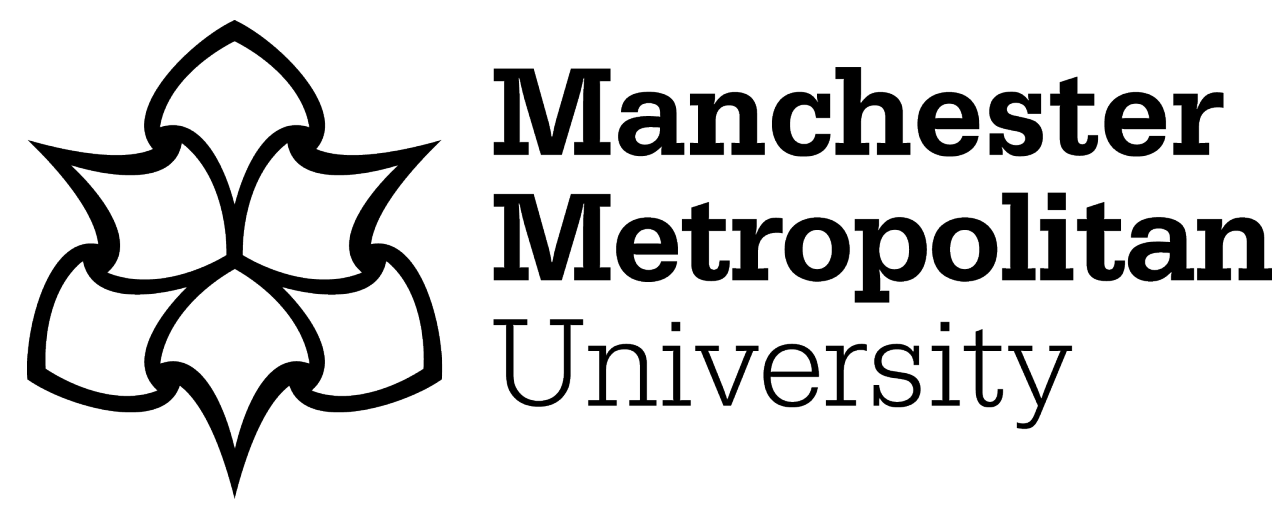

Atkinson, C ORCID logoORCID: https://orcid.org/0000-0002-3795-7442 and Hall, $L$ (2009) The role of gender in varying forms of flexible working. Gender, Work \& Organization, 16 (6). pp. 650-666. ISSN 1468-0432

Downloaded from: https://e-space.mmu.ac.uk/622981/

Version: Accepted Version

Publisher: Wiley Online Library

DOI: https://doi.org/10.1111/j.1468-0432.2009.00456.x

Please cite the published version 


\section{The Role of Gender in Varying Forms of Flexible Working}

\section{Carol Atkinson and Laura Hall}

In this article we present empirical data from a research study investigating the implementation of the flexible working policies that emanate from the improving working lives standard in a National Health Service Trust in the UK. We argue that gender is accorded insufficient focus in the literature, considering the barriers that create a take-up gap in formal flexible working practices. We further argue that gendered perceptions render unworkable attempts to portray flexible working as a gender-neutral issue and demonstrate that such perceptions mean that formal mechanisms for flexible working continue to be considered to be a women's issue. We present data on informal flexible working mechanisms and suggest that a greater focus on combining these mechanisms with formal flexibility may help provide working time flexibility for a greater proportion of the workforce.

Keywords: working time flexibility, gender, time sovereignty

\section{Introduction}

We report in this article on the efforts of one UK-based National Health flexible working policies which derive from the improving working lives (IWL) standard. We investigate the uptake of formal flexible working practices, identifying a number of barriers that are perceived to exist, and explore in particular those that relate to gender. We further explore informal flexibility mechanisms and their contribution to achieving flexibility for a diverse range of employees, considering the benefits that accrue from such approaches.

\section{Research context and concepts}

The flexibilization of the labour market provides the backdrop against which employees manage the reconciliation of family and employment in Britain 
(Brannen and Lewis, 2001). While the focus of such flexibilization fell initially on the need for greater flexibility from the workforce (Fagan, 2001), there has been increasing concern in more recent years over how to deliver flexible working options that benefit the workforce, often as a result of recruitment and retention difficulties (McBride, 2003). This is particularly important for those employers who, like the NHS, rely to a great extent on female employees (McBride, 2003). Lack of availability of flexible working hours, for example, was a key issue cited by former nurses in their decision to leave nursing (Smith and Secombe, 1998). These issues also extend to men, however, and it has been established that dissatisfaction with hours of work is a major cause of employee turnover among both sexes (Taylor, 2002). Such concerns led initially to the emergence of a family friendly agenda, in which policies focused on supporting employees in combining work and family pressures, developing more recently into an emphasis on achieving work-life balance or work-life integration, often via flexible working mechanisms.

While a largely voluntary approach to employers introducing flexible working policies has been applied (Harker and Lewis, 2001), such recruitment and retention difficulties have led the Labour government to adopt an interventionist approach to these issues in the NHS through its IWL standard. NHS managers are required to achieve the standard, which demands that a range of policies and practices are in place 'that enable staff to manage a healthy balance between their work and their commitments outside work' (Department of Health, 2000a, p. ix), one strand of such policies focusing on flexible working practices. Thus NHS human resources strategy (Department of Health, 2000b) and the IWL standard adopt the premise that flexible working practices can boost recruitment and retention, and the standard is intended to persuade NHS trusts to create policies that maximize employer benefits through the provision of employee benefits in the form of flexible working policies.

Such policies, agreed in an NHS context between the employer and trade unions, provide for the implementation of flexible working practices that are likely to include part-time working, career breaks, job sharing, term-time working and sabbaticals (Torrington et al., 2005). These practices create a formal route to flexible working via the contractual variation of working hours, often focusing on time reduction mechanisms. Part-time working, for example, falls in this category, as it gives an employee a contractual right to work an agreed number of reduced hours per week. It should be noted that there are also some such practices that focus on the arrangement rather than reduction of time, but nevertheless provide an employee with a contractual right to flexibility. Examples of this include compressed working weeks and flexitime schemes where employees work agreed core hours but are then permitted to arrange the balance of their working hours within certain agreed parameters. While they are flexible, in the sense that employees can reduce or vary their working time, these formal practices nevertheless impose 
structural and rigid solutions upon employers who are required to honour the arrangements (Hall and Atkinson, 2006).

As noted above, initial efforts in this field emphasized a need for family friendly policies, and much of the research evidence relates largely to the impact of flexible working and how it helps working mothers to manage work and home (Smithson and Stokoe, 2005). More recently, however, there has been an attempt to situate flexible working within a broader diversity agenda, suggesting that it is concerned with all employees and is an issue for all managers. Thus it is proposed that work-life balance

isn't just about women juggling a home and family.... It's also about adjusting working patterns so that everyone, regardless of age, race or gender, can find a rhythm that enables them more easily to combine work with their other responsibilities or aspirations.' (Department for Education and Employment, 2000, p. 4)

Thus, government and NHS aspirations are for working time flexibility to be available to all employees, and the need for this emanates not just from pressures such as the increase in dual career families but also from concerns over work intensification and the length of the working week in the UK (Green, 2001). The business case approach adopted by the government (Doherty, 2004) may be argued to be working, given the increase in policies to deliver working time flexibility reflected in the recent workplace employment relations survey 2004 findings (Department of Trade and Industry, 2006). However, as we note below, the existence of such policies does not necessarily ensure their effective implementation.

Recasting the agenda as a matter of diversity has led to the introduction of gender-neutral language in an attempt to put work-life issues in the mainstream of organizational policy (Kandola and Fullerton, 1994) and has led to adoption of gender blind terms (Smithson and Stokoe, 2005) such as flexible working, in order to move the debate away from the family and from being an issue for women (Cooper et al., 2001; Lewis, 2001). Smithson and Stokoe (2005) suggest, however, that the perception remains that flexible working is a women's issue, and further that the benefits accruing from it are seen as favours and not entitlements, thus leading to perceptions of unfair treatment that favours women (Lewis, 1997). It thus appears that little progress has been made in presenting working time flexibility as being relevant to all employees and we consider below why this may be, later suggesting that informal flexibility may help to achieve this.

There are a number of barriers traditionally identified as creating a take-up gap (Kodz et al., 2002), that is, the number of people who take flexible working options is much smaller than the number who desire greater worklife balance. Among the barriers typically identified is that there is a lack of awareness of flexible working policies (Skinner et al., 2004). Individuals also have to be proactive and come up with flexible solutions that meet business 
needs, which is difficult when there are few precedents and a lack of understanding of what is available or possible (IRS, 2002). Further, most organizations in an IRS survey had no procedure for employees to use to request flexible working (IRS, 2002) and management, or poor management skills, have been shown to present barriers to introducing and implementing worklife balance policies (Chartered Institute of Personnel and Development, 2003; Hall and Atkinson, 2005). Finally, employees consider that taking up such options suggests a lack of commitment to one's career and the organization, with potentially negative consequences (Rana, 2002).

We argue, however, that such barriers accord insufficient consideration to the issue of gender. These barriers apply to both men and women and yet evidence continues to suggest that flexible working opportunities are accessed to a far greater extent by women (Crompton, 2002). We suggest that the UK government's aspiration that flexible working is relevant to all employees, their egalitarian model, sits uncomfortably with a business case approach and state welfare policies that consider the family to be private matter (Den Dulk, 2004) and provide little support to working parents (Fagan, 2001), reinforcing the traditional male breadwinner model that has long dominated in the UK (Sheridan, 2004). This model reinforces working patterns whereby men typically work full-time, often long, hours while women work short part-time hours (Fagnani et al., 2004). Pay inequality (Sheridan, 2004), lack of affordable child care (Atkinson and Hall, 2006) and women continuing to shoulder the burden of domestic labour, even when in professional occupations (Lewis, 2001), are significant contributory factors to the continuation of this model.

It is not surprising then that a number of authors have reported that men tend not to work flexibly (see, for example, Sheridan, 2004) and relate this to gender roles. We argue that gender roles are a significant barrier to men accessing the formal flexible working practices described above, given the extent to which societal expectations in the UK remain gendered in relation to both men (Beck, 2000; Sheridan, 2004) and women (Smithson and Stokoe, 2005). Smithson and Stokoe (2005) support the argument that women continue in the main to adopt the primary caregiver role, while the male breadwinner role is still dominant. Many of the flexible working practices available, both generally and as part of the IWL standard, involve a reduction in working hours, for example, part-time working, job sharing or term-time only working.

It is acknowledged that a part-time wage cannot sustain a standard of living determined on the basis of a full-time wage (Rubery, 1998), creating a fundamental barrier to access for many men, and indeed single parents as well, who assume a breadwinner role and are unable to sustain a reduction in their salary as a result of their need to maintain the family income. We thus argue that men are more likely to be excluded than women on financial grounds from accessing flexible working options. We do not consider this to 
be inevitable, drawing on experience in Norway in which the state's adoption of a social justice approach to reconciling work and other commitments has led to a supportive welfare state and, in a relatively short period of 20 years, has seen a shift from a traditional to a far more egalitarian model in which men and women both typically work short full-time or long part-time hours (Den Dulk, 2004). Nevertheless, the findings we report are in the current UK context, there being no suggestion that the state has any intention to change its policy approach, and we consider gender barriers from that perspective.

We suggest that the career barriers noted above (Rana, 2002) are compounded by gender issues. Intensification of work has led to the assumption that work-life balance is not appropriate for professional and managerial roles and that long hours necessarily apply (Sheridan, 2004), so that women have to perform according to a male career model in order to be considered successful (Smithson and Stokoe, 2005). Professional men are thus rarely to be found working flexibly (Sheridan, 2004), although the burden of domestic labour falling upon women may mean that professional women are more likely to risk damage to their career by seeking to work flexibly than men (Lewis, 2001). Further, part time work is often less valued, as it is seen as cost saving and is applied to marginal roles usually carried out by women (Fagan, 2001). Gendered expectations thus again serve to create a situation where men, to a greater extent than women, exclude themselves from accessing flexible working options.

Given the influence gender has in influencing access to flexible working options, we support Sheridan (2004), who argues that having formal flexible working systems will not on their own change working practices and we suggest that there is a need to consider additional mechanisms that may be used to deliver flexibility in working time irrespective of gender roles. While formal flexibility may support certain types of employee, especially women with caring responsibilities, in combining paid employment and other commitments, it is likely that such formal approaches will need to be combined with other mechanisms in order to support a diverse range of employees in achieving work-life integration. The issue of time sovereignty (Fagan, 2001; Sheridan, 2004), which creates greater employee control over working schedules, as opposed to simply reducing working time, is beginning to emerge as such a mechanism. In this article, we define such employee control as informal flexibility and argue that, while it is harder to define than the formal flexibility, it may involve high levels of employee discretion over determining their working time, or ongoing negotiations with managers to arrange fluctuating working patterns that are conducive to reconciliation of work and other commitments. We suggest that time sovereignty cannot be formally arranged; rather, it is an approach that empowers employees to use discretion in arranging working time to fit other commitments on an ongoing basis, involving trust-based relations and a less reliance on the need for monitoring and controlling working time (Singe and Croucher, 2003). We 
draw on work such as Dex and Scheibel (2001) in which the informal application in small firms of flexible working practices designed to address individual circumstances is demonstrated both to respond to diverse employee needs and create a culture of reciprocity whereby employees feel obliged to respond flexibly to employer's needs. Such an approach rests heavily on relationships and expectations and is in contrast to the general provision of flexibility for the benefit of the employee that is situated within a formal policy framework such as the NHS, which seeks to build an image of good employer. We suggest that such formal practices have a critical role to play in achieving working time flexibility for certain groups, but that informal flexibility can complement these and provide access to working time flexibility for a more diverse range of employees.

While there is little research on the application of informal flexible working practices, it is possible to see how such an approach may address the specific gender barriers to formal flexible working practices discussed above. Control over working time to better suit individual circumstances, as opposed to a reduction in working time, provides benefit to both men and women irrespective of any male (or female) breadwinner role. Similarly, the negative career connotations of working part time or other forms of reduced hours may not apply with such informal mechanisms. Work in this area in the UK has, however, been confined to small firms that are often noted for their reliance on informality (Ram and Edwards, 2003). The extent to which larger firms, particularly those noted as being as bureaucratic as the NHS are able to adopt such mechanisms is questionable, although there is some evidence that firms in other European countries are beginning to experiment with this approach to working time flexibility (Singe and Croucher, 2003).

In response to the issues raised above we explore in this article the implementation of formal flexible working policies in an NHS trust, adopting a gendered perspective. We investigate the uptake of such practices and any barriers that are perceived to exist. We further explore informal flexibility mechanisms and their contribution to achieving flexibility for a diverse range of employees, considering the benefits that accrue from such approaches.

\section{Methodology}

The remit for the research on which this article is based was for us to work with an NHS trust to investigate the implementation of its flexible working policies situated within the IWL standard. The Trust expressed concerns that, while receiving good ratings on its policies, their implementation of such policies is less highly rated and asked us, firstly, to diagnose problems with this implementation and then propose remedies to help improve the way that flexible working policies are operating. Given that the rating of the IWL standard contributes to the Trust's overall star rating, the government's 
measure of a trust's performance, the Trust is keen to ensure that implementation of flexible working policies makes an appropriate contribution to its overall performance.

The findings presented in this article result from the analysis of 43 interviews and a focus group, followed up by associated questionnaire in the diagnosis phase of this research. The interview sample comprised 13 men (30 per cent) and 30 women (70 per cent), which broadly reflects the general pattern across the NHS (McBride, 2003). The interviews were carried out across five directorates and included a range of staff levels and job types (for example, joiners, catering staff, nurses, physiotherapists, accountants and administrative staff). A number of the employees we interviewed had either supervisory or managerial responsibility for staff, but in our interviews we were also clear that we wished to hear their views from the perspective of being an employee of the Trust, managed by others, as well as in their managerial role. The interviews were carried out between October and December 2004 and all but three interviews were tape recorded and then transcribed for analysis. The interviewees were all volunteers and were identified by a liaison person in each department we visited. This liaison person was always a manager but not necessarily the most senior person in the department. The researchers agreed the range of departments to be covered through the co-ordinator of the improving working lives subcommittee, this co-ordinator identifying the appropriate liaison person.

The interviews adopted a semi-structured approach that ensured that the issue of flexible working policies was central, while participants were not constrained in terms of raising issues that they believe to be relevant and important (Bryman, 1988). It was in adopting such a non-directive approach to interviews and asking interviewees to define for themselves what constitutes flexible working that the importance of the theme of informal flexible working practices, which is central to this article, emerged. Further, we did not adopt researcher-derived categories on the impact that flexible working policies may have on individuals, but asked about the type of flexibility that participants have, how important it is to them, their perceptions of why the Trust is interested in improving flexibility, and what the barriers may be. This format allowed employees in their own way to explain the meaning and sense that such policies make to them. Thus we avoided putting words in the mouths of participants and our analysis results from the idiosyncratic explanations of our respondents and our understanding of flexible working emerges from the participants' perceptions of their working environment.

In addition to the interviews a focus group was carried out with ten members of a nursing ward where a computerized self-rostering system was being piloted. This focus group led to the development of a questionnaire that was distributed to all members of the ward (46 in total). Fifteen completed questionnaires were returned and analysed. Secondary data in the form of employee opinion survey data and investors in people feedback were also 
used to inform the findings, together with Trust data on retention and absence, although this data added little to the understanding we developed through the interview and focus group processes.

\section{Findings and discussion}

In line with the inductive approach adopted, the interviews opened with participants being asked to express their understanding of flexible working; the expectation being that they would refer to the available formal flexible working practices that were most relevant to them or with which they were most familiar. In fact, most respondents defined flexible working in terms of the informal flexible working practices that they were able to access, indicating also that they considered such working arrangements as being to their benefit and as meeting their needs, rather than those of the Trust:

Being able to work when it's convenient really, I suppose, and if you need to have time off for whatever reason that the Trust will be, within reason obviously, try and accommodate you, if you needed time off for sick relatives or if you needed appointment time, things like that. (Woman dietician)

It seems strange, in an organization in which flexible working via the IWL standard is supposedly so prominent, that understandings of flexible working were rarely constructed around formal, policy-driven practices. The Trust's flexible working policy, focused on formal practices only, adopts a genderneutral language that suggests that it is applicable to all employees and, as such, is situated within the diversity policy. Communication of the policy, however, appears to be poor, as few participants were aware of the policy or where to locate it, which supports the Trust's view that IWL is not well implemented and reflects other research suggesting that a take-up gap in flexible working often results from poor communication and awareness (Skinner et al., 2004). It, perhaps also points to a need for flexibility that does not fall within the usual definitions and approaches, a theme to which we return later in the article.

Evidence did, however, emerge of formal flexible working practices, although this was limited. There was a high incidence of part-time working: of the 43 employees interviewed, 12 (28 per cent) worked on a part-time basis, all of whom were women. Indeed, part-time working was apparent to such an extent that many seemed not to view it as a flexible working practice, taking it almost for granted. While the small sample size is not of statistical significance, a pattern nevertheless begins to emerge of the gendered nature of formal flexible working practices, and this is explored further below.

Research has suggested that part-time work is often predominantly available in low skilled, marginal roles (Fagan, 2001) and while this was evident in 
the Trust in non-skilled roles, such as laundry workers, there was evidence of part-time professional roles. This was particularly so in the female-dominated professional areas, such as occupational health and physiotherapy, where the wealth of part-time working arrangements created complexity in work scheduling in a patient-facing setting. The more male-dominated, nonprofessional areas, however, continued to perceive part-time working and other forms of flexibility to be problematic:

Well, mainly, because I just think that work isn't everything today, that's all. I just think you come to work, do your job to the best of your ability, you may need to leave at times, you may need to have flexibility within working, for whatever reasons and I think that's got to be accommodated. I couldn't foresee a total flexibility within a production environment, I couldn't see that. But I am not saying it is not impossible, but I couldn't see a total flexibility within the shift patterns, if you like, and moving around within the shift patterns I think that would be difficult: you have to have stability. (Male laundry supervisor)

This perhaps reflects a theme in the literature that better educated and professional employees are able to benefit from flexible working options, whereas lower skilled workers are often disadvantaged by such schemes (Fagnani and Letablier, 2004). In the NHS context, where many of the professional areas are female dominated, this may serve to reinforce the gendered nature of formal flexible working practices.

Other than part-time working, formal flexible working practices were accessed by relatively few of the respondents, with some examples of formal flexitime schemes (seven employees) and access to carer leave entitlements (five employees). One employee compressed her hours into 4 days, one had previously taken a sabbatical and some of the participants made reference to colleagues who had taken career breaks, job shared or worked term time only, but a fairly limited range of examples emerged. The rhetoric of flexibility espoused in the flexible working policy did not, thus, appear to be translated into reality for most employees in respect of their working practices.

Those participants who had taken up formal flexible working options were asked their reasons for doing so. Most referred to childcare needs, with three indicating that they had elder care responsibilities. The participant quoted below worked on a part-time basis and described this arrangement thus:

Its quite important to me because I have two children at home. Obviously, sometimes you do worry that you are getting the balance right and.... it is of paramount importance to me. (Woman senior nurse)

Virtually no other reasons for working flexibly on a formal basis were cited. Thus, the formal mechanisms for flexible working were considered to be very important to those who accessed them, such access, other than flexitime schemes, was exclusively sought by women employees primarily for reasons 
of child or elder care and seemed to have little appeal to other groups of employees. Thus, the demand for flexible working appears to be driven by employees' caring responsibilities, the gendered nature of these (Smithson and Stokoe, 2005) serving to reinforce the perception that formal flexible working is a women's issue. Perceptions of flexible working practices, whether formal or informal, were positive:

I'm very satisfied the way I've been treated in here, definitely. They have been very helpful and I think a lot of places wouldn't meet you half way. I'm still doing 10 hours more than I actually did originally than when I first came but it's 7 hours less than [former employer]. (Woman administration officer)

These perceptions appear to support previous research suggesting that flexible working has positive benefits, serving to create an employment relationship in which discretionary behaviour may be demonstrated (Hall and Atkinson, 2005). The gendered nature of formal flexible working options did, however, serve to create negative perceptions of their unfair allocation and that those with young children were favoured:

Obviously, looking after the department or seeing people early and seeing people late tends to fall on the full timers, because a lot of the girls that are mums go home to pick the kids up from school so that late type of day always falls on to us. So, say a part timer would see a patient but they can only come late, you'll end up getting those patients as well, if you see what I mean. (Woman senior physiotherapist)

Those accessing formal flexible working options considered such working arrangements to be entitlements rather than favours, which contrasts with earlier work (Lewis, 1997). Despite this, allocation of such entitlements still led to perceptions that they created an unfair advantage for women with young children, those not accessing such options being left to cover for those who did. Thus, gendered perceptions of flexible working may actually serve to hinder its broader acceptance across a workforce. Despite its promotion in the diversity policy as being applicable to all employees, formal working time flexibility was constructed as a women's issue:

But as regards flexibility and working lives I think we are moving towards a flexible approach ... they really have accommodated today women having children sort of to the nth degree, I think they have really pulled out and done very well. (Male laundry supervisor)

The perception was reflected by both men and women that formal flexible working polices applied to women with childcare responsibilities, The extent to which this remains a women's issue, grounded in perceptions of their having a caring role, is perhaps demonstrated by one childless nurse who expressed her 6-month unpaid sabbatical to travel the world as being the 
maternity leave she had never had: thus even flexibility for reasons outside childcare is situated within a women's agenda.

Most of those interviewed did not perceive that formal flexible working options were of relevance to men. Those who did, however, expressed the perception that a male breadwinner role was a barrier to accessing such options:

I mean, from a personal point of view, I want to spend more time with my children and I don't see them that often in the sense that I am working Monday to Friday, the difficulty being is that it's difficult for me to take advantage [of formal flexible working] because of the level I am [senioritywise] and secondly, being the main earner... I can't drop hours because I'm the main earner and I have got bills to pay and that sort of thing, but I would like to take advantage. (Man, senior manager, finance)

This was a view expressed by a number of the men interviewed who had partners who either did not work outside the home or did so on a part-time basis, leaving them with the primary financial responsibility for the family. As noted earlier, none of the men interviewed worked on a part-time basis or on any other form of reduced hours, the only form of flexible working accessed by them being flexitime systems that did not reduce their earning capacity. Thus, gender roles that allocate a breadwinner responsibility to men lead the male participants in this study to consider themselves excluded from formal flexible working (Sheridan, 2004).

Gendered career patterns also appear to contribute to the lack of access to formal flexible working options, a macho (Smithson and Stokoe, 2005), long hours model that demonstrates the commitment to the organization that many assume to be required for career progression. This is alluded to in the above quote (man, senior manager, finance), that suggests that seniority in a role impedes access to flexible working options. The view was expressed that workloads at a senior manager level precluded any reduction in working hours and that, in any event, this was not appropriate as senior managers should lead by example.

However, while the barrier of career is cited in the literature as applying to both men and women at a senior level (Smithson and Stokoe, 2005), there is some evidence in the Trust that in the female-dominated professional areas this barrier is beginning to break down. One woman senior manager said that women managers were now more likely to feel able to access formal flexible working options, describing the contrast between her previous attempts to reduce her working hours and have a later starting time and the current approach:

I think that things have definitely changed here. I mean the NHS generally over the last 10 years. When I went back after having my daughter.... I felt quite vulnerable really, going to my manager and saying, 'Can I come in a 
bit later?' You know, I felt quite threatened about that and I actually did come up against bias where it was, 'Well, you're a manager and you can't do that.' I don't think that's there now. I feel 10 years ago that was the case. I was actually told by my Manager that you can't do that.... IWL has helped, there are a lot more policies out there helping families and just education. (Woman, senior manager, medical records)

The shifting perceptions seemed allied in part to the directorate in which the employees worked. The senior managers in departments such as finance and administration, who were predominantly male, still seemed to perceive a need for long hours to demonstrate commitment to their career. In the medical and nursing departments, however, there were a small number of women who worked part time at a senior level and perceived that they could maintain, if not necessarily progress, their career while working more flexibly. The gendered context in which formal flexible working is conducted may thus have significant impact on the extent to which it is seen as career limiting.

Our data thus reflect an underreported barrier to formal flexible working, that of gender and gendered roles and perceptions. It is apparent that formal mechanisms for flexibility are important and valued but that these appear more relevant to particular groups of employees than others and our data have led us to the opinion that formal mechanisms for the reduction of working time may always be less relevant for certain groups than others. However, we argue that the pursuit of working time flexibility for a wide range of employees may be well served by time arrangement mechanisms of a predominantly informal type. We turn now to consider the data in respect of informal flexibility and demonstrate how this provides access to working time flexibility for a more diverse range of employees.

Data from a self-rostering pilot on a nursing ward pilot indicated that this formal mechanism of flexible working was not highly valued by employees, contrary to much of the evidence in this area (Wortley and Grierson-Hill, 2003). The nurses did not on the whole perceive that self-rostering had enhanced their working lot, suggesting that the self-rostering process allowed for little influence over the rosters beyond making the initial requests. The underlying reason for the nurses' antipathy towards self-rostering appeared to be the loss of highly valued informal systems of arranging working time. Perceptions of the system are well expressed by the following extract:

It was easy to see what other people were requesting. If you went to it and saw that other people had requested a Saturday off and you wanted it ... you'd maybe just then go to other people and ... ask to swap. With the [new process] you can't see what anybody else is requesting. (Self-rostering trial focus group transcript)

The importance of informal flexibility demonstrated in the self-rostering pilot is reflected throughout our findings. Employees seek and value informal 
mechanisms for arranging their working time. Nearly all those interviewed cited examples of informal mechanisms adopted, either on a routine or an ad hoc basis. For example, one nurse had an informal understanding with her manager that she would always arrive late on a certain day in order to accommodate the medical needs of her elderly mother, but that she would make the time up at other (unspecified) times in the week. Others simply gave examples of working with their manager to agree ad hoc arrangements that allowed them to fulfil personal commitments or deal with problems outside work as they arose, to swap shifts or even to finish work early if service demands were low:

I just know that if I do have a problem, I usually go to my manager and she will try and sort out for me to have some time off if I need it. (Woman nurse)

Such arrangements were highly valued and were perceived to apply to all those interviewed, both men and women and professional or managerial workers and operatives, with no apparent differences between departments. While the perception was expressed that even informal flexibility may be unfairly allocated to women with young children, on the whole such flexibility was considered to be widely applied. This informal flexibility, or time sovereignty (Sheridan, 2004), affords a high degree of control over working time that is highly valued by employees (Hall and Atkinson, 2006).

This emphasis on informal flexibility may be explained by its relevance to all employees in providing time arrangement mechanisms that assist with combining work and other commitments, rather than the formal time reduction mechanisms, that, while valued by those who accessed them, were in this study relevant to only a small group of employees. Informal flexibility helps to achieve this balance without requiring a reduction in salary (Fagan, 2001) or risking the negative impact on career (Smithson and Stokoe, 2005) associated with formal flexible working mechanisms. Informal flexibility may thus complement formal flexibility and may be less constrained by considerations of gender.

There was general acceptance that such informality and flexibility should be reciprocated on the part of employees, as opposed to the sense of entitlement that was associated with formal flexible working arrangements. There was evidence that the Trust required employees to work flexibly for its benefit and that they accepted this with a significant focus on the need to deliver service to a high standard in most cases:

Well, I think it [flexible working] means me being able to be flexible and my employers being able to be flexible so that if I need to perhaps change my hours for any personal reason, then I can ask that, and if they needed me to be flexible with how I work to fit in with what the needs were on the ward then I would also do that. (Woman senior occupational therapist) 
Such reciprocity has obvious benefits for both parties and seems to arise in a way that does not occur with formal flexibility. It should be noted, however, that a small number of employees expressed concerns about this reciprocity, suggesting that the manager could manipulate this dynamic to force them to work harder and that they felt potentially vulnerable to managerial attempts at work intensification.

In summary, formal flexible working options were accessed by some employees and were highly valued by and beneficial to these employees. There was a perception, however, that such options were gendered and were 'for women' and those men who suggested that they may be interested in them identified financial and professional barriers to accessing them. From the inductive approach adopted to data collection, however, it emerged that there is a significant emphasis on informal flexibility, that this is highly valued and perceived to apply to a wide range of employees, although in a minority of cases women with young children are still perceived to benefit from it, to the disadvantage of others. Such informal flexibility also generates reciprocity with significant benefits to both parties to the employment relationship, although vulnerability to work intensification is a potential issue.

\section{Conclusions}

In this article we demonstrate that the take-up of formal flexible working practices is constrained by gender roles and argue that attempts to render flexible working or work-life balance gender neutral by situating it in a diversity policy will be unsuccessful and may indeed serve to reinforce gendered perceptions of flexible working policies. We demonstrate that the existence of a flexible working policy will support changes to the working time of certain groups of employees, but many employees will be unaffected by such policies. We provide evidence in particular directorates of the impact that recruitment and retention difficulties can have on changing working practice, although these directorates are largely female dominated, but such options are accessed by a relatively small group of employees. Lack of awareness and poor communication of flexible working policies may contribute to this, but it is also a function of gendered perceptions of roles, meaning that many employees cannot avail themselves of time reduction mechanisms as a result of financial or career barriers.

What emerges clearly from our data is the importance of informal flexibility to a diverse range of staff who use it to balance their working lives with a wide range of external commitments. For example, male employees who adopted a breadwinner role adopted informal flexibility to integrate work and other commitments without a consequent reduction in salary. Such informal flexibility similarly did not impact negatively on perceptions of commitment to career and career progression. 
Informal flexibility also generates perceptions of reciprocity that appeared to be welcomed by both parties and served to ensure service delivery was effective, although it should be noted that there were some concerns over its potential to lead to work intensification. We do not suggest that informal flexibility is a substitute for formal, but that the two approaches can complement in each other in meeting the diverse needs of employees in different ways. We argue that such mechanisms are currently under-researched in the wider work-life balance debate and call for further research in this area. We further argue that the role of gender in inhibiting the uptake of formal flexible working practices is underexplored and, again, needs further research. We argue that this results from gendered roles being less relevant to informal flexibility.

We suggest that formal flexible working practices have a key role to play in supporting employees to achieve working time flexibility and that benefits from this accrue to the employer organization. We recognize, however, that such practices are perceived as relevant to particular groups of employees and, while we believe that access to these practices could be enhanced by improvements in organizational practice, we argue that, on their own, they are unlikely to achieve their aim of providing working time flexibility to all employees. We suggest that greater recognition is required of the role of informal flexibility in creating such working time flexibility for a diverse range of employees, particularly given the benefits they create for the employer in terms of service delivery and to the employee in terms of balancing work and other commitments. We suggest that the role of informal flexibility is currently underrepresented in the literature and that, combined, both types of flexibility could be powerful in improving working time flexibility for employees.

The single case study approach used to gather this empirical data means that it cannot currently be used to generalize further and the additional research outlined above would serve to build upon our findings. Further we recognize that our consultancy approach to the research, coupled with a small sample drawn from a group of volunteers, creates limitations for our findings. Nevertheless, we argue that our work provides potentially important new insights to the debate on flexible working that it would be worthwhile to pursue further.

\section{References}

Atkinson, C. and Hall, L. (2006) Work organisation and flexibility. In Lucas, R., Lupton, B. and Mathieson, H. (eds) HRM in an international context, pp. 173-98. London: Chartered Institute of Personnel and Development.

Beck, U. (2000) The Brave New World of Work. Cambridge: Polity Press.

Brannen, J. and Lewis, S. (2001) Workplace change and family life. Report on two case studies. Manchester: Work-life Research Centre.

Bryman, A.E. (1988) Doing Research in Organisations. London: Routledge. 
Chartered Institute of Personnel and Development (2003) Managers obstruct flexibility. People Management, 9,18, 9.

Cooper, C., Lewis, S., Smithson, J. and Dyer, J. (2001) Report on Stage One of Flexible Futures. London: Institute of Chartered Accountants in England and Wales.

Crompton, R. (2002) Employment, flexible working and the family. British Journal of Sociology, 53,4, 537-58.

Den Dulk, L. (2004) Transitions. Gender, parenthood and the changing European workplace, Research Report no. 2: Literature review for the EU Framework 5 funded study. Manchester: Research Institute for Health and Social Change, Manchester Metropolitan University.

Department for Education and Employment (2000) Creating a work-life balance: a good practice guide for employers. Sudbury: DFEE.

Department of Health (2000a) The NHS plan. A plan for investment, a plan for reform Leeds: NHS.

Department of Health (2000b) Working lives: programmes for change. Leeds: NHS.

Department of Trade and Industry (2006) Inside the workplace: findings from the 2004 Workplace Employment Relations Survey. London: DTI.

Dex, S. and Scheibel, F. (2001) Flexible and family-friendly working arrangements in UK-based SMEs: business cases. British Journal of Industrial Relations, 39,3, 41131.

Doherty, L. (2004) Work-life balance initiatives: implications for women. Employee Relations, 26,4, 433-52.

Fagan, C. (2001) Time, money and the gender order: work orientations and working -time preferences in Britain. Gender, Work \& Organization, 8,3, 239-66.

Fagnani, J., Houriet-Ségard, G. and Bédouin, S. (2004) Transitions research report 1: Context mapping for the EU framework 5 funded study, 'Gender, parenthood and the changing European workplace'. Manchester: Research Institute for Health and Social Change, Manchester Metropolitan University.

Fagnani, J. and Letablier, M-T. (2004) Work and family life balance: the impact of the 35-hours law in France. Work, Employment \& Society, 18,3, 551-72.

Green, F. (2001) It's been a hard day's night: the concentration and intensification of work in late twentieth century Britain. British Journal of Industrial Relations, 39,1, 53-80.

Hall, L. and Atkinson, C. (2005) The impact of work-life integration policies on performance. Paper read at the Third Performance and Reward Conference, Manchester Metropolitan University, April 7.

Hall, L. and Atkinson, C. (2006) Improving working lives: flexible working and the role of employee control. Employee Relations, 28,4, 374-86.

Harker, L. and Lewis, S. (2001) Work-life policies: where should the government go next? In Birkett, N. (ed.) A Life's Work: Achieving Full and Fulfilling Employment, pp. 123-37. London: Institute of Public Policy Research.

IRS (2002) Hanging in the balance. IRS Employment Review, 766, 6-11.

Kandola, R. and Fullerton, J. (1994) Managing the Mosaic. London: Institute of Personnel and Development.

Kodz, J., Harper, H. and Dench, S. (2002) Work-life Balance: Beyond the Rhetoric. Brighton: Institute for Employment Studies.

Lewis, S. (1997) Family friendly policies. A route to changing organizations or playing around at the margins? Gender, Work \& Organization, 4,1, 13-23.

Lewis, S. (2001) Restructuring workplace cultures: the ultimate family-friendly challenge? Women in Management Review, 16,1, 21-9.

McBride, A. (2003) Reconciling competing pressures for working-time flexibility: an impossible task in the NHS? Work, Employment \& Society, 17,1, 159-70. 
Ram, M. and Edwards, P. (2003) Praising Caesar not burying him: what we know about employment relations in small firms. Work, Employment $\mathcal{E}$ Society, 17,4, 719-30.

Rana, E. (2002) Balancing Act Earns UK Respect: the Guide to Work-life Balance. London: Chartered Institute of Personnel and Development.

Rubery, J. (1998) Part-time work: a threat to labour standards? In O'Reilly, J. and Fagan, C. (eds) Part-time Prospects, An International Comparison of Part-time Work in Europe, North America and the Pacific Rim, pp. 130-44. London: Routledge.

Sheridan, A. (2004) Chronic presenteeism: the multiple dimensions to men's absence from part-time work. Gender, Work and Organization, 11,2, 207-25.

Singe, I. and Croucher, R. (2003) The management of trust-based working time in Germany. Personnel Review, 32,4, 492-509.

Skinner, D., Saunders, M.N.K. and Duckett, H. (2004) Policies, promises and trust: improving working lives in the NHS. International Journal of Public Sector Management, 17,7, 558-70.

Smith, G. and Secombe, I. (1998) Changing Times: a Survey of Registered Nurses in 1998. Brighton: Institute for Employment Studies.

Smithson, J. and Stokoe, E.H. (2005) Discourses of work-life balance: negotiating 'genderblind' terms in organizations. Gender, Work \& Organization, 12,2, 147-68.

Taylor, S. (2002) The Employee Retention Handbook. London: Chartered Institute of Personnel and Development.

Torrington, D., Hall, L. and Taylor, S. (2005) Human Resource Management, 6th edn. Harlow: Prentice Hall.

Wortley, V. and Grierson-Hill, L. (2003) Developing a successful self-rostering system. Nursing Standard, 17,42, 40-2. 